\title{
Trabalho familiar ou assalariamento? Dilema de jovens em comunidades rurais
}

\section{Family work or working for wage? Dilemma of young people in rural communities}

Ketiane dos Santos Alves - Mestre em Agriculturas Familiares e Desenvolvimento Sustentável pelo Núcleo de Ciências Agrárias e Desenvolvimento Rural (NCADR) da Universidade Federal do Pará (UFPA) Belém-PA. E-mail: ketiane_alves@hotmail.com

Dalva Maria da Mota - Doutora em Sociologia, pesquisadora da Embrapa Amazônia Oriental (Belém, Pará) e professora do Programa de Pós-Graduação em Agriculturas Familiares e Desenvolvimento Sustentável da UFPA Belém-PA. Bolsista de produtividade do CNPq. E-mail: dalva.mota@ embrapa.br.

\section{Resumo}

Neste artigo, analisamos as estratégias de trabalho de jovens em unidades de produção agrícola no nordeste do Pará, região com fortes limitações quanto aos recursos naturais. A pesquisa foi realizada em 2010, por meio de um estudo de caso na comunidade Nossa Senhora de Lourdes, município de Mãe do Rio. Os principais resultados mostram que $\mathrm{O}$ padrão de exploração do meio natural com base na agricultura de corte e na queima em áreas de apenas 25 hectares tem ocasionado problemas associados ao esgotamento dos recursos naturais. Em consequência, reconfiguram-se os arranjos no âmbito do trabalho, especialmente dos jovens, que buscam novas alternativas por meio do assalariamento, pretendendo, com isso, obter recursos mais rapidamente e construir os seus projetos de autonomia. Essa situação tem aumentado a demanda de contratação de mão de obra nas suas unidades de origem e o peso do trabalho para os que ali permanecem.

\section{Palavras-chave}

Juventude. Assalariamento. Organização do trabalho familiar.

\begin{abstract}
The objective of this work was to analyze working strategies used by young people in the agricultural production with strong natural limitations in northeastern Pará. A case study was carried out in 2010 in the community of Nossa Senhora de Lourdes, in the municipality of Mãe do Rio. The main results show that the slash-and-burn based model of natural exploitation in areas of 25 ha has caused great problems associated with the depletion of natural resources. Thus, the work strategies, especially among the young people are being rearranged. They now seek wage-earning activities as an alternative to obtain incomes faster and to develop their autonomy projects. This new reality has promoted changes in manpower demand and hiring in their units of origin and an overload of work for the people who remain in the family work.
\end{abstract}

\section{Keywords}

Young people. Wage-earning activities. Family work organization. 


\section{INTRODUÇÃO}

Neste artigo tratamos da relação entre os jovens e o trabalho no âmbito de uma pesquisa mais ampla sobre a relação entre família e trabalho no espaço rural. Com base em Wanderley (2007), consideraremos como jovens todos aqueles que estão em um momento do ciclo da vida denominado juventude, caracterizado como um período de transição entre a infância e a idade adulta. Culturalmente determinada, a demarcação dessa etapa de vida é sempre imprecisa, estando ligada ao fim dos estudos, ao início da vida profissional, à saída da casa paterna ou à constituição de uma nova família ou, ainda, simplesmente a uma faixa etária (WANDERLEY, 2007).

Estudos recentes mostram que a juventude rural não é uma categoria homogênea, mas é marcada por uma diversidade relacionada a contextos econômicos, sociais e políticos específicos e dinâmicos (ABRAMO, 2007; ABRAMOVAY, 1998; CARNEIRO, 1998; CASTRO, 2005; STROPASOLAS 2002; WANDERLEY, 2003). Nesses termos, os grupos aos quais os jovens pertencem têm situações sociais, espaciais e históricas diversas e adotam múltiplas estratégias de reprodução social (MALAGODI; MARQUES, 2007, p. 197) que podem se caracterizar, por exemplo, pelo envolvimento dos jovens na unidade de produção familiar, pela migração para trabalhos temporários para complementar a renda da família ou como projeto do próprio jovem, pelo investimento na educação formal visando à qualificação para outras profissões (MALAGODI; MARQUES, 2007; STROPASOLAS, 2002).

De acordo com Malagodi e Marques (2007, p. 198), na agricultura familiar, o ato de "ficar ou sair", de "ir e vir" dos jovens são estratégias complementares pautadas por condições objetivas e subjetivas das famílias, marcadas por fatores de exclusão - como a falta de acesso a terras, a impossibilidade de herança da propriedade familiar, a posse de áreas com tamanho insuficiente para o desenvolvimento do trabalho de todos os membros da família em uma mesma unidade de exploração agrícola - ou por projetos individuais elaborados pelos jovens, na perspectiva de alcançar melhores condições de vida. Para esses autores, "ficar ou sair" são opções que ocultam, de um lado, "valores que se formam na mente dos jovens a partir das condições de que dispõem suas famílias" e de seus meios de produção e, de outro, alternativas de desenvolvimento de atividades nos espaços rurais ou fora deles (MALAGODI; MARQUES, 2007, p. 198).

Wanderley (2007) destaca que o jovem rural, ao estruturar o seu projeto de vida, enfrenta tensões não vividas pelos jovens urbanos. A primeira delas surge quando o jovem do campo pergunta-se o que quer ser, o que fazer e onde: no

Novos Cadernos NAEA, v. 16, n. 1, Suplemento, p. 163-180, jun. 2013 
campo ou na cidade? (WANDERLEY, 2007). Isso porque sua socialização no processo de trabalho agrícola familiar difere da socialização de um jovem no meio urbano (WEISHEIMER, 2004). A segunda refere-se à relação com a família: para os jovens do meio rural, a família também representa uma unidade produtora, que exige de seus membros relações de solidariedade e disponibilidade de mão de obra. Assim, "quando um jovem formula seu projeto de vida, deve levar em conta o seu papel nessa unidade e seu compromisso com relação à família e sua unidade de produção" (WANDERLEY, 2007, p. 68). Nesse sentido, a dúvida entre "ficar ou sair", "ir e vir" não seria apenas uma questão estruturante, mas estaria ligada a particularidades de uma referência identitária e a valores morais, relacionados, por sua vez, principalmente, com as etapas de socialização do trabalho agrícola ao longo do tempo. A "inserção dos jovens no trabalho agrícola ocorre desde a infância e desempenha um papel fundamental na construção de sua identidade social, já que estes são parte de um trabalhador coletivo: a família" (WEISHEIMER, 2004, p. 102).

Tendo em conta a especificidade da relação do jovem com a sua família no espaço rural, analisaremos neste artigo as estratégias de trabalho dos jovens na organização do trabalho de famílias da comunidade Nossa Senhora de Lourdes, município de Mãe do Rio no Nordeste paraense, cujos estabelecimentos agrícolas possuem fortes limitações quanto aos recursos naturais. Ali, evidências empíricas indicam a existência de um aparente contraste que instigou a escolha do tema: por um lado, a comprovação de que as limitações do meio natural têm influído na crescente demanda de trabalho no estabelecimento (ALVES, 2011); por outro, relatos orais, segundo os quais os jovens homens, cada vez mais, assalariavam-se fora do estabelecimento dos seus pais.

A pesquisa constou de levantamento de dados secundários (estatísticas e documentos institucionais sobre a região e seus habitantes) e primários, obtidos por meio de observação participante, entrevistas estruturadas e semiestruturadas realizadas com membros de 15 famílias sobre a história da ocupação da área, a composição familiar, os ciclos de desenvolvimento, a gestão das unidades de produção e a perspectiva das famílias e dos jovens, no que diz respeito ao trabalho na agricultura e em outras atividades.

O artigo é composto de quatro partes: além desta introdução, um segundo capítulo aborda o acesso aos recursos naturais na comunidade Nossa Senhora de Lourdes; e um terceiro, o trabalho dos jovens da comunidade e os arranjos quanto à organização do trabalho familiar; em seguida, tecem-se as considerações finais. 


\title{
1 O ACESSO AOS RECURSOS NATURAIS NA COMUNIDADE NOSSA SENHORA DE LOURDES
}

\author{
1.1 Um pouco da história
}

A ocupação da região na qual se situa Nossa Senhora de Lourdes data da década de 70 do século XX. A exploração do meio natural passou por três fases: a) extração madeireira; b) pecuária extensiva; c) atividades agrícolas com agricultura itinerante ${ }^{1}$ a partir da chegada de "posseiros" a essas áreas.

Os processos sociais que marcaram a ocupação da região refletem as políticas de desenvolvimento para o nordeste paraense. Como analisa Conceição (2002), a construção da rodovia Belém-Brasília e a política de incentivos fiscais estimularam, na década de 1970, o estabelecimento de grandes fazendas na região. Nesse período, as áreas às margens da rodovia foram ocupadas por grupos de empresários (madeireiros e fazendeiros) que exploraram conjuntamente as áreas de florestas primárias na seguinte sequência: exploração intensiva do potencial madeireiro, seguida da queima das áreas exploradas objetivando a "limpeza de terras", e constituição de pastagens para o desenvolvimento da pecuária bovina extensiva.

Em Nossa Senhora de Lourdes, o desmatamento também teve início na década de 1970 com a instalação de grupos envolvidos na exploração madeireira e na formação de grandes fazendas. Na década de 1980, inicia-se o primeiro processo de ocupação dessas áreas por famílias de agricultores que viviam na região à procura de "terras de trabalho". Dentre eles, destacam-se ex-seringueiros que, após o declínio da atividade de extração do látex, continuaram na região na perspectiva de encontrar outras formas de sobrevivência (ALVES, 2011).

O acesso à terra se deu por meio de um processo de "ocupação", sob condições de tensão e enfrentamento com fazendeiros. Nessa "ocupação", cada família demarcou lotes de aproximadamente 25 hectares. A fase de instalação das famílias caracterizou-se pela abertura de novas áreas de matas e capoeiras para o estabelecimento de lavouras destinadas ao consumo familiar. A cada ciclo agrícola as áreas cortadas e queimadas para a implantação de roçados sofriam perdas de solos, aumento da acidez e porosidade, redução da infiltração e da

\footnotetext{
1 A agricultura itinerante é um sistema agrícola primitivo, historicamente utilizado nos ecossistemas de florestas tropicais na Amazônia. Nesse sistema, o homem derruba um trecho da floresta, queimando-o como preparo da terra, geralmente para cultivos alimentares. São sistemas que envolvem frequentemente a limpeza de terrenos, seguida por vários anos de colheita até que o solo perca a fertilidade natural. Assim, a área é deixada em pousio, e são abertas novas áreas de florestas até que a área em pousio recupere a sua produtividade.
}

Novos Cadernos NAEA, v. 16, n. 1, Suplemento, p. 163-180, jun. 2013 
biodiversidade vegetal, o que afetou principalmente o banco de sementes. Esse quadro já havia sido percebido em áreas de ocupação mais antigas do nordeste paraense (ÉGLER, 1961; PENTEADO, 1967).

Em 1989, com a redução das áreas de florestas nos lotes, as famílias começaram a implantar roçados maiores de mandioca em áreas de capoeirão (capoeiras altas) e a reservar as roças apenas para o aprovisionamento, tendo em vista a possibilidade de fabricação de farinha para a comercialização no mercado local da sede do município de Mãe do Rio. A ampliação das áreas cultivadas tem relação também com a maior disponibilidade da mão de obra dos filhos.

Em 1993, com o início do "ciclo da goma ou fécula de mandioca", as famílias intensificaram seus roçados e começaram a implantá-los em áreas maiores (10 a 24 tarefas - 0,003 a 0,007 hectare) em decorrência da rentabilidade da goma de mandioca, cuja fabricação exigia menor tempo e disponibilidade do trabalho da família e cuja comercialização gerava uma renda imediata. No entanto, os entrevistados reconhecem que foi nessa fase que as terras sofreram maiores ações antrópicas, uma vez que a produção da goma exigia uma quantidade significativa de tubérculos e, consequentemente, a implantação de maiores áreas cultivadas.

Aliado a isso, no ano de 2000, o acesso ao crédito rural direcionado à pecuária bovina fez com que essas famílias incorporassem aos seus sistemas de produção áreas de pastagens para a criação de bovinos como forma de investimento ou como uma garantia de renda segura, em caso de necessidade de obtenção imediata de recursos financeiros (um caso de doença na família, a perda da produção do ciclo, a compra de insumos etc.). De acordo com os entrevistados, nesse período, as áreas que ainda possuíam boa capacidade de produção para o cultivo da mandioca foram utilizadas para a implantação de pastos.

Segundo os entrevistados, até 2006, as famílias da comunidade tiveram como principal atividade geradora de renda a fabricação da fécula da mandioca. Todavia, com a chegada à região, em 2006, de empresas que comercializavam a fécula industrializada, esta atividade deixou de ser praticada, pois o valor do produto industrializado vendido no mercado local era inferior ao valor da fécula produzida pelos agricultores. O fim desse ciclo foi também um marco na percepção do desgaste das áreas cultivadas na comunidade. Naquele período, o meio natural das unidades de produção das famílias apresentava fortes limitações quanto à fertilidade dos solos, o que indicava baixa capacidade produtiva, uma vez que já não possuíam possibilidades de itinerância (rotatividade) nos seus estabelecimentos. Assim, as famílias começaram a recorrer às áreas de parentes 
ou amigos para cultivar mediante acordos ${ }^{2}$ ou reduziram as áreas de seus roçados.

\subsection{Um novo contexto}

Dadas as dificuldades mencionadas, as famílias voltaram a produzir mandioca para transformá-la em farinha, objetivando o consumo e a venda, visto que essa atividade não exige grandes áreas cultivadas e o produto constitui o principal item da alimentação. Ademais, a mandioca pode ser colhida entre dois e três ciclos agrícolas. Transformada em farinha, encarna aquilo que Heredia (1979) denominou "alternatividade": o produto, além de servir como fonte de alimento da família, pode ser comercializado em qualquer época do ano; logo, o agricultor pode obter recursos financeiros durante todo o ciclo.

Durante todos esses anos, os agricultores continuaram a utilizar o sistema de corte e queima, mesmo em áreas de capoeiras baixas ou em áreas de capim. Atualmente a cobertura vegetal dessas unidades é constituída em sua maioria por capim-estrepe $(57,14 \%)$, pastagens $(32,10 \%)$, capoeira fina $(3,64 \%)$ e pequenas áreas de roças $(0,005 \%)$ e de matas ciliares $(0,0001 \%)$. Os altos percentuais de pastagens e de capim-estrepe devem-se ao acesso ao crédito para a prática da bovinocultura no ano de 2000, e ao abandono gradual dessas áreas de pastagens anos mais tarde, por causa da impossibilidade de criação de bovinos em pequenas terras de 25 hectares.

De acordo com os agricultores entrevistados, a repetição do mesmo método de plantio durante décadas, a redução dos períodos de pousio (período de 1 a 2 anos de pousio) e o uso do fogo como elemento principal de preparação de roças têm deixado a terra totalmente comprometida por processos erosivos com redução da capacidade de infiltração de água - e compactada - com baixa fertilidade para a implantação de novos cultivos.

Com a implantação de pequenas áreas de roçados, as famílias traçam novas estratégias, entre as quais a incorporação de adubos e defensivos químicos (por 90\% dos agricultores estudados) ao longo do processo, aumentando assim os custos de produção, sem que aumentem os preços dos produtos cultivados nos estabelecimentos agrícolas.

Das 15 famílias estudadas, $40 \%$ possuem terras para plantio, porém com baixa fertilidade, por isso utilizam terras de terceiros; $40 \%$ não plantam em áreas

\footnotetext{
Em 2006, como as famílias dispunham de poucas terras com capacidade produtiva e parcos recursos financeiros para aumentar sua produtividade por meio do uso de insumos (adubos, fertilizantes etc.), passaram a cultivar em terras de terceiros, estabelecendo acordos de parcerias, arrendamentos e meias de produção.
}

Novos Cadernos NAEA, v. 16, n. 1, Suplemento, p. 163-180, jun. 2013 
de terceiros, mas oferecem suas terras para outras famílias implantarem roças sob condições de troca de dias, meias ou até mesmo no sistema de arrendamento (das famílias que possuem áreas de pastos encapoeiradas (enjuquiradas); 20\% não usam terras de terceiros, nem oferecem terras a terceiros).

Para as famílias que arrendam terras de terceiros, o custo de cada tarefa arrendada equivale a $\mathrm{R} \$ 40,00$ (quarenta reais ciclo) e muitas vezes a parte da produção retirada da área, o que representa um aumento significativo nos custos dessa produção. Além dos roçados implantados em áreas de terceiros, essas famílias ainda precisam dispor de insumos e de mão de obra familiar para manejar as pequenas áreas de roçados implantados tanto no lote da família quanto no lote de terceiros.

A situação-limite do meio tem influenciado a organização do trabalho familiar, uma vez que, ao mesmo tempo que a família demanda mão de obra dos seus membros para manterem as atividades na sua unidade de produção, os filhos jovens homens tendem a procurar alternativas de trabalho para garantir outras fontes de recursos financeiros. Para 58\% dos entrevistados, essa situação gera um desequilíbrio entre a produção e o consumo.

\section{O TRABALHO DOS JOVENS DA COMUNIDADE E OS ARRANJOS QUANTO À ORGANIZAÇÃO DO TRABALHO FAMILIAR}

Como tratado na literatura, os jovens filhos de agricultores familiares pertencem a famílias nas quais se confundem a unidade de consumo e de produção. Sua socialização no processo do trabalho agrícola familiar difere da socialização dos jovens no meio urbano dada a sua inserção nas relações sociais de produção e de reprodução da agricultura familiar (WEISHEIMER, 2004).

Mesmo que as constatações de Weisheimer correspondam ao que observamos em campo, é importante ressaltar os novos termos do debate sobre o problema do trabalho infantil. Afirmam Sarmento e Stropasolas (2010, p. 19):

Diversas iniciativas e ações concretas orientadas à eliminação do trabalho infantil vêm sendo implementadas em nível de sociedade, Estado, organizações internacionais, ONGs, etc., fundamentadas no aparato legal de proibição do trabalho de crianças, e no alicerce simbólico e valorativo construído por instituições internacionais (OIT, ONU, etc.), com o apoio dos governos, que deslegitimam a sua prática social.

Muito embora não seja esse o tema central do nosso artigo, concordamos com os autores que, em se tratando da inserção de crianças e jovens nas atividades 
agrícolas, é necessário diferenciar as atividades que fazem parte de um processo de socialização no seio de estratégias de "autorreprodução, indispensável para o fortalecimento dos laços familiares, para a construção da distinção entre a fase adulta e a meninice e para a aprendizagem das técnicas de lidar com os ecossistemas dos quais fazem parte" (CARDOSO; SOUZA, 2011, p. 165), da exploração do trabalho infantil sob a regência de terceiros.

Como identificado por Sarmento e Stropasolas (2010), as crianças e os adolescentes da comunidade Nossa Senhora de Lourdes vivenciam na socialização um conjunto de papéis sociais, diferenciados por gênero e por geração, regidos por regras, hierarquias e poderes expressos na divisão do trabalho agrícola familiar. Aos meninos, são ensinados o "trabalhar na roça, o fazer produzir" e, às meninas, ensina-se a "manter a organização da casa, cumprir com os afazeres domésticos", numa relação acentuada de "espaços de produção e reprodução".

No decorrer da socialização, aos jovens são conferidos papéis sociais próprios. Sua inserção na força de trabalho representa sua integração parcial ao "mundo adulto", pois eles estão em preparação para adquirir o pleno conhecimento do conjunto de atividades da unidade produtiva. Nesse sentido, a participação dos jovens homens na divisão do trabalho familiar geralmente ocorre em atividades ligadas à preparação de áreas, à plantação, à colheita e principalmente aos tratos com as culturas, muitas vezes roça e capina, que exigem principalmente resistência física de quem as pratica.

Para compreender as posições ocupadas pelos jovens na organização do trabalho familiar, construímos a Tabela 1, a qual apresenta a média de participação dos membros nos trabalhos familiares das unidades de produção estudadas.

Tabela 1 - Posições ocupadas pelos membros na organização de trabalho familiar

\begin{tabular}{|c|c|c|c|c|c|c|c|c|}
\hline \multirow{2}{*}{$\begin{array}{l}\text { Tipo de } \\
\text { trabalho }\end{array}$} & \multicolumn{8}{|c|}{ Quem executa (\%) } \\
\hline & Pai & Mãe & Casal & Filho & Filha & $\begin{array}{l}\text { Pais e } \\
\text { filhos }\end{array}$ & $\begin{array}{l}\text { Mãe e } \\
\text { filhas }\end{array}$ & Todos \\
\hline Administrativo & 50,3 & 8,2 & 11,4 & 0 & 0 & 30,1 & 0 & 0 \\
\hline Agrícola & 6,6 & 0 & 14,8 & 0 & 0 & 56,6 & 0 & 22 \\
\hline Doméstico & 0 & 42,1 & 26,3 & 0 & 0 & 10,52 & 15,78 & 5,3 \\
\hline
\end{tabular}

Fonte: Pesquisa de campo (2010)

Conforme especificado, o trabalho nas unidades de produção das famílias estudadas divide-se em três tipos de atividades principais: administrativas, agrícolas e domésticas. As atividades administrativas, ligadas à comercialização dos produtos agrícolas, à realização de serviços bancários, ao acesso ao credito e à compra de insumos são assumidas (50,3\%) pelo homem adulto (pai), que 
desempenha o papel de chefe da família; 30,1\% dessas atividades também são executadas por filhos mais velhos, principalmente quando o chefe da família é idoso e o seu estado de saúde impõe-lhe restrições. Nesse caso, o pai consulta os filhos adultos para a tomada das principais decisões quanto à gestão do lote. Entretanto, planejam e executam juntos grande parte dos trabalhos que envolvem o sistema de produção familiar. É importante destacar que, mesmo que assuma qualquer tarefa com o pai, o filho dificilmente a executará sem seu auxílio ou aconselhamento. Essa autoridade é fundamentada pelo fato de ser o pai o detentor do saber agrícola que transforma a terra em trabalho e que "autoriza e dirige o processo de trabalho na unidade produtiva" (WOORTMANN; WOORTMANN, 1997, p. 13). Ainda que não possua grande vigor físico para realizar determinadas atividades, o pai é considerado como força plena dentro da unidade de produção, pois é ele quem define e reúne todas as condições de organização do processo de trabalho da família (WEISHEIMER, 2004). Nesse caso, o reconhecimento dos filhos enquanto agricultores capazes de assumir responsabilidades nas tarefas do sistema de produção é alcançado quando se percebe o domínio do "saber fazer" da agricultura e a maturidade de fazer determinados trabalhos até então não executados na fase da "meninez".

No trabalho agrícola, pais e filhos (jovens e adultos) responsabilizam-se por $56,6 \%$ das tarefas ligadas à produção de mandioca (para produção de farinha), milho e feijão - este último para o consumo da família. Os filhos (jovens) têm peso na participação nessas atividades, pois são eles que suprem grande parte da força de trabalho em atividades de preparo de áreas, plantio e principalmente nos tratos com as culturas, como, por exemplo, a capina, que exige tempo, disponibilidade e resistência física, por ser uma tarefa geralmente desenvolvida durante vários dias com exposição ao sol. No caso das famílias estudadas, apenas $40 \%$ possuem terras disponíveis para plantios. Por causa da baixa fertilidade de suas terras, essas famílias utilizam áreas arrendadas de terceiros para garantir uma produtividade que seja minimamente capaz de manter seus membros e cobrir os custos de suas unidades de produção. Nessas situações, os pais, juntamente com os filhos, trabalham dentro e fora do lote da família, o que ocasiona um acúmulo de atividades.

Em 14,8\% dos casos, observa-se a participação exclusiva do casal nas atividades agrícolas. Isso ocorre geralmente quando os filhos migram para outros locais à procura de novos postos de trabalhos regulares ou mesmo temporários,

\footnotetext{
"Meninez" é o termo utilizado pelos agricultores para designar a fase em que os jovens ainda não adquiriram responsabilidade para assumir atividades desempenhadas pelos adultos no roçado. No caso aqui exemplificado, a fase de meninez refere-se à pouca maturidade dos jovens com relação ao trabalho na unidade de produção familiar.
} 
em estabelecimentos agrícolas vizinhos. Nessas situações, o casal assume toda a responsabilidade, o que significa uma sobrecarga, visto que a maioria não dispõe de recursos financeiros para contratar trabalhadores temporários. Como explicou uma entrevistada:

Hoje meu marido planeja fazer as coisas e faz sozinho, pois os filhos estão todos trabalhando fora. Mas quando os meninos vão para a roça fazem serviço "pesado" junto com o pai, roça, capina, faz tudo que o pai deles faz. Mas quando meninos saem para trabalhar fora, o pai deles se sobrecarrega, quando tem, paga, quando não tem, vai fazendo o serviço sozinho, mas, se quando ele vê que não dá conta, o serviço espera, é o jeito! (M. R. F, 54 anos, agricultora da comunidade Nossa Senhora de Lourdes).

Em 6,6\% dos casos, o pai acaba executando a tarefa sozinho, seja porque a esposa não tem habilidade para as tarefas do roçado, seja porque os filhos pequenos exigem a permanência da mãe em casa, para prepará-los para a escola.

A colheita da mandioca e o trabalho de processamento da farinha são as atividades que mais absorvem a mão de obra da família - a média da participação de todos os membros nessas atividades é de $22 \%$. Isso pode ser justificado pelo fato de o produto (mandioca) exigir rapidamente a sua transformação (farinha) antes de iniciar a sua decomposição natural e, principalmente, por servir para o consumo da família e oferecer-lhe a possibilidade de um retorno financeiro imediato com a sua comercialização.

Constatamos que a força de trabalho dos jovens tem grande importância no grupo pesquisado. Assim como observado por Weisheimer (2004), os jovens aparecem desempenhando tarefas com toda a família, em determinados períodos do ciclo agrícola. Há situações em que os rapazes são os únicos responsáveis pelas atividades agrícolas, assumindo o trato dos pequenos animais, a limpeza de galinheiros e outras tarefas domésticas. Mas todas elas podem ser realizadas por qualquer membro da família. Diferentemente, Weisheimer (2004) observou no Rio Grande do Sul jovens com certa autonomia manejando parte dos cultivos da plantação até a colheita, na perspectiva de obterem uma renda própria. $\mathrm{Na}$ comunidade Nossa Senhora de Lourdes, essa situação não é possível, pela falta de terras e pelos parcos recursos financeiros disponíveis.

No que tange ao trabalho doméstico, ele é frequentemente identificado como responsabilidade das mulheres. Em 42,1\% dos casos, é a mãe sozinha quem realiza as tarefas da casa. Esse percentual deve-se principalmente ao fato de as entrevistadas atribuírem à mulher "mãe de família" a responsabilidade pelo bom andamento do lar e pela provisão dos familiares. Em 15,78\%, essa participação se da em conjunto com as filhas, as quais realizam atividades como

Novos Cadernos NAEA, v. 16, n. 1, Suplemento, p. 163-180, jun. 2013 
o preparo de refeições, limpeza da casa e dos quintais e lavagem de roupas. No entanto, nos casos estudados não se constatou um engessamento de papéis na divisão do trabalho, uma vez que existem famílias formadas apenas por um casal e famílias formadas por homens que também realizam as tarefas consideradas como domésticas, totalizando uma participação média de 26,3\% e 10,52\%, respectivamente. Concordamos com Maués (1993), quando afirma que os trabalhos feitos pelas mulheres são considerados domésticos e o que o homem faz é tido como produtivo. Ora, a autora afirma que não é a natureza do trabalho que o torna produtivo ou doméstico; é o sexo do indivíduo que o realiza.

Nesse sentido, o trabalho das filhas (jovens) nas atividades agrícolas é quase invisível, pois são geralmente orientadas a realizar atividades domésticas juntamente com a mãe e, em função da proximidade da cidade, são estimuladas a estudar na sede do município. Essa iniciativa constitui uma estratégia futura de gestão da sucessão do patrimônio familiar, porque diminuirá a pressão sobre os herdeiros do estabelecimento. Tendo a possibilidade de estudar fora, as jovens estarão habilitadas a conseguir um emprego na cidade.

Embora a força de trabalho do jovem seja importante para a execução dos trabalhos agrícolas e domésticos, é comum na comunidade os jovens saírem à procura de novas ocupações, para com isso obterem recursos mais rapidamente, atender aos seus desejos de consumo a construirem os seus projetos de autonomia.

Esse fenômeno deve-se frequentemente à falta de condições de trabalho no próprio estabelecimento em decorrência dos problemas já citados. Assim, os que permanecem no estabelecimento reorganizam o trabalho a ser feito.

Do total dos entrevistados, 73,4\% afirmam que a agricultura não tem conseguido proporcionar a obtenção de uma renda suficiente para manter o trabalho dos filhos em uma mesma unidade de produção agrícola. Por isso, alternativas são buscadas, como se depreende do depoimento a seguir:

Antigamente nós trabalhava todo mundo junto, tudo que a gente conseguia fazer era pra família. Hoje os meus filhos trabalha pra nós na roça e para outros, porque o que tá dando na nossa terra não tá dando pra eles manter a necessidade dos compromissos deles. Aí eles trabalham de alugado em outros lotes. Quer dizer que, quando o lote precisa, muitas vezes os meninos estão com outros serviços por aí. Aí sabe o que acontece? Eu vou ter que me virar pra pagar trabalhador de alugado, pois eu chego e falo assim: "Olha, tem um serviço pra fazer". E quando a gente vem pra planejar eles já estão com outros compromissos, aí eu tenho que esperar ou pagar, né! Essa é uma dificuldade grande que a gente vê aqui! (A. J. M., 51 anos, agricultor da comunidade Nossa Senhora de Lourdes). 
O relato permite constatar que a inserção dos membros das famílias em outras atividades tem causado efeitos nas unidades produtivas, não somente no que se refere aos arranjos nos papéis ocupacionais dos membros, mas também em outras relações, como o aumento dos custos de produção, com a contratação eventual de trabalhadores, e a sobrecarga de trabalho para os membros que usam integralmente sua força de trabalho. Permite também verificar que a possibilidade de busca de autonomia dos jovens para além da família não consta no repertório de explicações, muito embora haja evidências da compreensão de suas necessidades de consumo atuais.

Apesar das explicações, foi constatada a insatisfação dos pais, que precisam do trabalho de seus membros no estabelecimento, os quais, ao mesmo tempo, vendem sua força de trabalho a terceiros.

É como eu dizia, isso gera essa crise, esse desconforto pra família, por quê? Porque eu acho que, por exemplo aqui, aqui o papai na maioria das vezes parte do serviço ele faz só, sai de manhã, chega meio dia, aí sai de novo, chega à noite, e geralmente é assim que funciona (M. B. S., 35 anos, agricultor da comunidade Nossa Senhora de Lourdes).

Do total das famílias estudadas, $73 \%$ possuem jovens trabalhando fora da unidade de produção familiar e $27 \%$ possuem membros que trabalham apenas no lote. No primeiro grupo, constatamos que 61,6\% possuem membros que trabalham tanto na unidade de produção familiar como em unidades de produção de terceiros; 2,3\% têm membros que trabalham em outros municípios; 9,1\% das famílias possuem membros residindo e trabalhando na sede do município de Mãe do Rio ou em municípios vizinhos.

As atividades mais frequentemente realizadas por $70,7 \%$ dos jovens que vendem a sua força de trabalho em estabelecimentos vizinhos são: preparo de áreas para implantação de cultivos, capina, construção de cercas, carregamento e raspagem (descascamento) de mandioca em períodos de fabricação de farinha. Os demais $2,3 \%$ que trabalham em outros municípios são caseiros em fazendas, trabalhadores braçais em empresas de mineração, carregadores de cargas em supermercados e balconistas de lojas.

As ocupações fora do lote acarretam uma sobrecarga de trabalho para os membros que permanecem no estabelecimento. Por exemplo, a capina, que absorve boa parte do tempo de trabalho, geralmente fica sob o encargo do pai. Os filhos, por sua vez, assalariam-se nessa mesma atividade em estabelecimentos vizinhos.

De acordo com os entrevistados, os jovens começam a assalariar-se com 17 anos, fase em que estão em pleno vigor físico. Com essa iniciativa, eles Novos Cadernos NAEA, v. 16, n. 1, Suplemento, p. 163-180, jun. 2013 
buscam também a concretização dos seus projetos de autonomia, por meio da poupança de recursos para a implantação de pequenas roças, a compra de animais e motocicletas, e até mesmo a compra do direito de uso de lotes em áreas de reforma agrária em localidades vizinhas.

Nesse contexto, como Malagodi e Marques (2007,p. 202), sustentamos “que os jovens do meio rural possuem demandas específicas [...]; dadas as condições objetivas não satisfeitas nesse espaço, os jovens tendem a procurar outros aportes que envolvam seus projetos". Nesses casos, as demandas insatisfeitas, aliadas ao conjunto de dificuldades vividas no núcleo familiar, aparecem como o principal elemento motivador da saída desses jovens de suas comunidades (MALAGODI; MARQUES, 2007).

Para os jovens da comunidade Nossa Senhora de Lourdes, o trabalho agrícola no lote da família não contribui para que eles tenham renda monetária própria, num contexto em que se ampliam os desejos de consumo. Nesse sentido, "ter renda própria", independente da renda familiar, satisfaz necessidades individuais e específicas (como perfumes, roupas, sapatos, etc.). Explica um agricultor entrevistado:

O filho vai fazer um serviço fora, naquele serviço ele tem um dinheiro naquela mesma hora. O pai precisa - "meu filho venha pra cá". O filho fica pensando - "aqui eu tenho dinheiro na hora, mas aqui em casa eu só vou ter o dinheiro daqui a dez meses, e assim mesmo o dinheiro não vem todo pra mim”. Então ele prefere fazer o serviço fora. Agora, quando é que ele avalia que é vantagem fazer um serviço em casa? Quando é um serviço que o dinheiro vem muito rápido, tipo a farinhada, isso termina gerando uma tensão. Porque o pai diz: "eu preciso desse filho e esse filho não vem me acudir". E o filho diz: "eu bem que queria acudir em casa, mas em casa não tem dinheiro pra mim, então eu prefiro trabalhar aqui porque eu também tenho meus compromissos” (M. B. S., 35 anos, agricultor da comunidade Nossa Senhora de Lourdes).

Tanto os jovens de Nossa Senhora de Lourdes, quanto os jovens estudados por Malagodi e Marques (2007) estão integrados à cultura da juventude local, rural ou urbana, que, por sua vez, participa de um universo cultural amplo (globalizado) e que, para satisfazer a demandas específicas, necessita realizar atividades que lhe garantam renda monetária. Dessa forma, tanto o assalariamento, como as atividades eventuais realizadas fora da unidade de produção familiar são estratégias que visam à obtenção de alguma forma de renda monetária, mas, de modo algum podem representar uma ruptura com o trabalho no âmbito da família e com o seu lugar de origem (MALAGODI; MARQUES, 2007). 
Wanderley (2003) acrescenta que essa situação é bem presente na agricultura familiar. O "sair" ou o "ir e vir" dos membros não significa necessariamente o rompimento dos laços de família, mas uma fase da juventude, marcada por inúmeros movimentos. Um exemplo dessa constatação é o fato de os jovens de Nossa Senhora de Lourdes preferirem trabalhar em localidades vizinhas das suas unidades de produção. Assim, podem "ir" trabalhar e "regressar" diariamente, diminuindo os custos com moradia e alimentação e poupando mais dinheiro. Do ponto de vista dos pais, entretanto, essa situação não é tão confortável, porque a despesa com o consumo desses membros continua a mesma, mas eles não mais oferecem trabalho ao estabelecimento familiar. Assim, em determinados períodos do ano eles consomem e não trabalham no lote, o que acaba ocasionando certo desequilíbrio entre o que se produz e o que se gasta na unidade de produção.

Visto por outro prisma, o trabalho fora oferece aos jovens maior volume e independência quanto ao uso dos recursos. Mas, por outro lado, contribui para o aumento dos custos de produção da unidade produtiva, pela necessidade de contratação de trabalhadores temporários.

As tentativas dos jovens de realização de seus projetos incidem diretamente nas estratégias da unidade de produção e de reprodução da família. $\mathrm{O}$ assalariamento fora do estabelecimento em determinados momentos implica uma reorganização dos arranjos familiares. Além de simplesmente ficar ou sair, os jovens fazem escolhas diante das alternativas que possuem em suas condições objetivas.

\section{CONSIDERAÇÕES FINAIS}

A ideia central do artigo foi analisar as estratégias de trabalho de jovens pertencentes a famílias cujas unidades de produção têm fortes limitações quanto aos recursos naturais no espaço rural. A pesquisa foi realizada com famílias residentes na comunidade Nossa Senhora de Lourdes, município de Mãe do Rio, no nordeste paraense.

Nesse contexto, concluímos que o padrão de exploração do meio natural por meio da agricultura de corte e queima em áreas de apenas 25 hectares, ao longo de anos, tem ocasionado problemas associados ao esgotamento dos recursos naturais, dada a impossibilidade de períodos de pousio, essenciais para a regeneração dos recursos. Assim, as condições de produção caracterizam-se pela pequena dimensão das áreas disponíveis para o plantio, pela baixa capacidade produtiva dos solos e pela pouca diversidade dos sistemas de produção. $O$ fato de as famílias plantarem atualmente em áreas de pastagens enjuquiradas, sob

Novos Cadernos NAEA, v. 16, n. 1, Suplemento, p. 163-180, jun. 2013 
condições menos favoráveis do que no período em que nessas áreas havia matas ou capoeiras exige que elas reestruturem as suas práticas para permanecerem trabalhando na terra.

Em consequência da situação-limite do meio, concluímos que duas situações coexistem. A primeira é a reestruturação das estratégias e práticas agrícolas. Intensifica-se o arrendamento de terras de terceiros para a implantação de roçados. Nesse tipo de relação, além de aumentarem os seus custos de produção com o pagamento da unidade de área arrendada, as famílias precisam dispor de uma quantidade maior de mão de obra para manejar roçados dentro e fora dos seus estabelecimentos. Quanto às práticas, as etapas de broca e derruba praticamente inexistem, sendo realizadas as etapas de roçado, queima e limpas constantes. Apesar disso, a remuneração do trabalho situa-se no limite do aprovisionamento da família.

A segunda consequência é a reestruturação dos arranjos no âmbito da organização do trabalho diante de uma situação paradoxal: mais trabalho e menos mão de obra. Isso porque diminui a participação dos jovens nas atividades produtivas da família. Eles buscam novas alternativas de renda por meio do assalariamento. Pretendem, com isso, obter recursos mais rapidamente para atender a seus desejos de consumo, mas também investem na construção de seus projetos de autonomia. Essa situação tem causado uma carência de mão de obra nos estabelecimentos da família, suprida pela contratação ocasional de jovens diaristas oriundos de estabelecimentos vizinhos. Constatamos que se agrava, ainda assim, o peso do trabalho para os que permanecem no estabelecimento.

Com essa constatação, concluímos que há, entre os estabelecimentos, um intercâmbio de contratação de trabalhadores jovens, estimulado, de um lado, pelo aumento da demanda de trabalho, dada a condição-limite do meio, e, de outro, pela possibilidade que cada jovem tem de obter recursos mais rapidamente para as suas necessidades, diferentemente do que ocorreria no trabalho no estabelecimento da própria família. Nesse último caso, a recompensa pelo trabalho dos filhos resulta de outros requisitos não apenas monetários e sujeitos às necessidades prementes da família.

Quanto à distribuição do trabalho entre os membros da família, constatamos que a presença dos filhos no estabelecimento leva a uma distribuição mais equitativa da força de trabalho. Com a saída deles para trabalhar como assalariados, outros membros se desdobram e fazem uma parte do que a eles competia. Para o que não conseguem realizar, contratam trabalhadores. Mesmo assim, concluímos que aumentou a exploração do trabalho dos membros da familia que permanecem no lote. 
A destinação dos recursos ganhos pelos jovens por meio do trabalho assalariado varia: há aqueles que entregam regularmente uma quantia aos pais e os que dão apenas se lhes for pedido. Mas concluímos que há uma compreensão dos pais quanto às novas necessidades de dinheiro dos mais jovens. Citam-se palavras de um entrevistado: "[o dinheiro é] para usar o que os outros usam e eu não posso dar".

Para finalizar, admitimos que, embora as atividades exercidas pelos jovens fora das propriedades familiares ofereçam autonomia e permitam a aquisição de certos bens de consumo, em certa medida são igualmente precárias e incapazes de abrir novos campos profissionais para eles (WANDERLEY, 2007).

Nesse contexto, poder vivenciar o mundo do trabalho nas unidades familiares de produção e outras situações fora dessa realidade é, sem dúvida, o desejo dos jovens da comunidade Nossa Senhora de Lourdes, que enfrentam, entretanto, um dilema: alguns desejariam continuar trabalhando para a família, se existissem maiores alternativas de rendas outros anseiam encontrar fora da atividade agrícola o acesso aos meios que permitem a realização de outros projetos de vida, longe da agricultura. Em todos, porém, há a vontade de vencer o isolamento e a falta de oportunidades vividos naquele determinado espaço social.

\section{REFERÊNCIAS}

ABRAMO, H. W. Considerações sobre a tematização social da juventude no Brasil. In: CARNEIRO, M. J.; CASTRO, E. G. de (Orgs.). Juventude rural em perspectiva. Rio de Janeiro: Mauad, 2007.

ABRAMOVAY, R.et al. Juventude e agricultura familiar: desafios dos novos padrões sucessórios. Brasília, DF: UNESCO, 1998.

ALVES, K. dos S. Organização do trabalho de famílias agricultoras na comunidade Nossa Senhora de Lourdes, Nordeste Paraense. 2011. $126 f$. Dissertação (Mestrado em Agriculturas Amazônicas) - Núcleo de Ciências Agrárias e Desenvolvimento Rural, Universidade Federal do Pará, Belém, 2011.

CARDOSO, L. F. C.; SOUZA, J. L. C. de. Viver, aprender e trabalhar: habitus e socialização de crianças em uma comunidade de pescadores da Amazônia. Boletim do Museu Paraense Emílio Goeldi, Ciências Humanas, Belém, v. 6, n. 1, p. 165-177, jan./abr. 2011. 
CARNEIRO, M. J. Memória, esquecimento e etnicidade na transmissão do patrimônio familiar. In: CARNEIRO, M. J. et al. Campo aberto, o rural no Estado do Rio de Janeiro. Rio de Janeiro: Contra Capa, 1998. v. 1. p. 273-296.

CASTRO, E. G. de. O paradoxo "ficar" e "sair": caminhos para o debate sobre a juventude rural. In: SILVA, R.; FERRANTE, V. L. S. B.; ALY JUNIOR, O. Assentamentos rurais: impasses e dilemas (uma trajetória de 20 anos). São Paulo: INCRA, 2005. p. 321-349.

CONCEIÇÃO, M. de F. C. da. Reprodução social da agricultura familiar: um novo desafio para a sociedade agrária do Nordeste paraense. In: HÉBETTE, J.; MAGALHÃES, S. B.; MANESCHY, M. C. (Org.). No mar, nos rios e na fronteira: fases do campesinato no Pará. Belém: UFPA, 2002. p. 9-259.

ÉGLER, E. G.. A Zona Bragantina no Estado do Pará. Revista Brasileira de Geografia, Rio de Janeiro, v. 23, n. 3, p. 527-555, jul./set. 1961.

HEREDIA, B. M. A. de. A morada da vida: trabalho familiar de pequenos produtores do Nordeste do Brasil. Rio de Janeiro: Paz e Terra, 1979. 164 p.

MALAGODI, E.; MARQUES, R. Para além de ficar ou sair: as estratégias de reprodução social de jovem em assentamentos rurais. In: CARNEIRO, M. J.; CASTRO, E. G. de (Orgs.). Juventude rural em perspectiva. Rio de Janeiro: Mauad X, 2007. p. 197-214.

MAUÉS, M. A. M. “Trabalhadeiras" e “camarados": relações de gênero, simbolismo e ritualização numa comunidade amazônica. Belém: UFPA, 1993.

PENTEADO, A. R. Problemas de colonização e uso da terra na região Bragantina do Estado do Pará. Belém: UFPA, 1967. v. 1.

SARMENTO, M. J.; STROPASOLAS, V. L. Os sentidos do trabalho infantil no campo. Travessias Revista de Ciências Sociais e Humanas em Língua Portuguesa, Braga, Portugal, n. 10, p. 233-263, 2010.

STROPASOLAS, V. L. O mundo rural no horizonte dos jovens: o caso dos filhos de agricultores familiares de Outro (SC). Florianópolis: UFSC, 2002.

WANDERLEY, Maria de Nazareth Baudel. Jovens rurais de pequenos municípios de Pernambuco: que sonhos para o futuro. In: CARNEIRO, M. J.; CASTRO, E. G. de (Orgs.). Juventude rural em perspectiva. Rio de Janeiro: Mauad X, 2007. p. 21-34.

Agricultura familiar e campesinato: rupturas e continuidade. Estudos Sociedade e Agricultura, Rio de Janeiro, n. 21, p. 42-61, out. 2003. 
WEISHEIMER, N. Os jovens agricultores e seus projetos profissionais: um estudo de caso no bairro Escadinhas, Feliz/RS. 2004. 216f. Dissertação (Mestrado em Sociologia) - Universidade Federal do Rio Grande do Sul, Porto Alegre, 2004.

WOORTMANN, E.; WOORTMANN, K. O trabalho da terra: a lógica e a simbólica da lavoura camponesa. Brasília, DF: UnB, 1997. 192p. 